\title{
REOPERATION FOLLOWING TOTAL REPAIR OF CONGENITAL HEART DISEASE
}

\author{
Tadashi Isomura, M.D., Kouichi Hisatomi, M.D., Fuminiko Andoh, M.D. \\ Takemi Kawara, M.D., Akio Hirano, M.D., Ken-ichi Kosuga, M.D. \\ AND Kiroku OHISHI, M.D.
}

\begin{abstract}
For the past 25 years we have performed 61 reoperations in 58 patients with congenital heart disease who previously underwent total correction for the diagnosed ventricular septal defect, tetralogy of Fallot, atrioventricular septal defect, atrial septal defect, total anomalous pulmonary venous connection (TAPVC), and other involvement for $27,11,5,4,4$, and 7 patients, respectively. Causes of reoperation included 43 events of valvular lesion, 29 of residual septal defect, 5 of conduit failure, 5 of venous obstruction, 3 of hemolysis, 3 of infective endocarditis, and 2 of prosthetic valve dysfunction. Although 5 early and 4 late deaths were encountered, the remaining 49 patients ( 3 in New York Heart Association (NYHA) Class II and 46 in NYHA class I or II) survived the reoperation.

The patients were followed up by echocardiography and chest X-ray examination, and reoperation was indicated under the following conditions: moderate to severe valvular insufficiency; residual defect causing the shunt ratio to be over $30 \%$ or a systolic pulmonary pressure over $50 \mathrm{mmHg}$; or a high pressure gradient over $50 \mathrm{mmHg}$ across the right ventricular outflow tract. Early timing for reoperation seemed to be important in patients with pulmonary venous obstruction, prosthetic dysfunction, severe hemolysis and infective endocarditis.
\end{abstract}

$\mathbf{W}^{\mathrm{m}}$

TH advances in cardiovascular surgery and increasingly improved survival rates after operation in congenital heart disease (CHD) patients, the frequency of reoperation subsequent to previous repair has been increasing. In the past decade, CHD surgery has been more complicated and has occurred earlier stages; thus reoperations in the late follow-up period have become more frequent. In some cases a prior correction for CHD has been designed as an approach to the successfully staged intracardiac repair! In this report, we present $58 \mathrm{CHD}$ patients

Key words:

Reoperation

Congenital heart disease

Residual lesions who underwent reoperation; recommended indications for reoperation, including the problem of its timing, are also discussed.

\section{PATIENTS AND METHODS}

In the past 25 years, 58 patients with open heart surgery followed by reoperation were seen at the Second Department of Surgery in Kurume University Hospital. Clinical data at their previous operation (Table I) showed preoperative diagnoses comprised 27 ventricular septal defect (VSD) patients, 11 tetralogy of Fallot (TOF), 5 atrioventricular canal defect (AVCD), 4 atrial septal defect, 4 total anomalous pulmonary venous connection (TAPVC), 2 transposition of great

(Received May 7, 1990; accepted September 18, 1990)

The Second Department of Surgery, Kurume University Hospital, Kurume, Japan

Mailing address: Tadashi Isomura, M.D., The Second Department of Surgery, Kurume University Hospital, 67 Asahi-Machi, Kurume, Fukuoka 830, Japan 
TABLE I CLINICAL FEATURES IN 58 CASES

\begin{tabular}{|c|c|}
\hline Initial DX (No. of patients) & Associated lesion or type of lesion (No. of patients) \\
\hline$V S D(27)$ & $\begin{array}{l}\text { Isolated (10), AR (7), PS (4), MR (1), TR (1), AS, PS (1), PDA, MR } \\
\text { (1), PDA, IAA (1), CoA (1) }\end{array}$ \\
\hline$T O F(11)$ & $\begin{array}{l}\text { RVOT stenosis: Infundibular and Valvular (6), Infundibular (4), Valvu- } \\
\text { lar (1) }\end{array}$ \\
\hline$A-V C D(5)$ & Complete (3) Incomplete (2) \\
\hline$A S D(4)$ & Isolated (3), TR (1) \\
\hline$T A P V C$ (4) & Supracardiac (1) Cardiac (3) \\
\hline Others (7) & DORV (2), TGA (2), Truncus Arteriosus (2), Congenital AR (1) \\
\hline
\end{tabular}

Abbreviation: $D x=$ diagnosis; $V S D=$ ventricular septal defect; $A R=$ aortic regurgitation; $P S=$ pulmonary stenosis; $M R=$ mitral regurgitation; $T R=$ tricuspid regurgitation; $A S=$ aortic stenosis; $P D A=$ patent ductus arteriosus; IAA=interrupted aortic arch; $\operatorname{CoA}=$ coarctation of aorta; TOF=tetralogy of Fallot; RVOT=right ventricular outflow tract; $A-V C D=$ atrioventricular canal defect; $A S D=$ atrial septal defect; $T A P V C=$ total anomalous pulmonary venous connection; DORV=double outlet right ventricle; $T G A=$ transposition of great arteries

arteries and 5 other anomalies. Ages ranged from 38 days to 41 years. Follow-up lasted one month to 17 years. Patients were routinely monitored with the cardio-thoracic ratio (CTR), electrocardiogram (ECG), changes in heart murmur and, since 1981, echocardiogram. In patients with an increased CTR or significant heart murmur concomitant with residual shunt, moderate to severe valvular regurgitation or a pressure gradient across the right ventricular outflow tract (RVOT) over 30 to $50 \mathrm{mmHg}$ on doppler echocardiogram, cardiac catheterization was added to identify residual lesions.

Stenosis of RVOT was evaluated by the pressure gradient between the pulmonary artery and right ventricle. In residual septal defect cases, the shunt ratio was calculated from the routine cardiac catheterization data and in hemolysis cases the hematological parameter of anemia and serum levels of lactate dehydrogenase, free hemoglobin, and bilirubin were measured. In case of prolonged fever of unknown origin, a blood culture was repeated to disclose septicemia. Cases of a sudden onset of congestive heart failure after prosthetic valve replacement and repair of TAPVC were carefully sought for possible causes of such symptoms.

\section{RESULTS}

Ninety postoperative events necessitated reoperation in 58 patients (Table II). Of 43 valvular lesions (Table III), aortic regurgitation (AR) occurred in 12 patients including 6 after aortic valvuloplasty and one after aortic valve replacement; tricuspid regurgitation (TR) in 10 after VSD closure and residual TR in 2 with complete A-VCD after tricuspid annuloplasty (one VSD-associated TR and one ASD-associated TR; and mitral regurgitation (MR) in 5 after repair of other lesions and residual MR in 6.

Of 29 residual septal defects, residual VSD occurred in 24 patients including 8 after closure of VSD and 9 after total correction of TOF, and residual ASD in 5 comprising 3 after closure of isolated ASD, one after repair of A-VCD, and one after repair of double outlet right ventricle (DORV). Of 5 patients with conduit failure, one with transposition of great arteries (TGA) received a Hancock valved conduit at a previous Rastelli's operation and its replacement 5 years and 6 months later; one with pseudotruncus arteriosus received a Teflon graft at a previous reconstruction of the aorta and its replacement 9 years and 5 months later because of relative stenosis of the graft conduit 
TABLE II RESIDUAL LESIONS (No. of patients)

\begin{tabular}{|c|c|}
\hline Valvular lesions (43): & $\begin{array}{l}A R(12), T R(12), M R(11), \\
P S(7), P R(1)\end{array}$ \\
\hline $\begin{array}{l}\text { Residual septal } \\
\text { defect (29): }\end{array}$ & $\operatorname{VSD}(24), A S D$ \\
\hline Conduit failure (5): & $\begin{array}{l}\text { Homograft (3), Valved con- } \\
\text { duit (1), Teflon graft (I) }\end{array}$ \\
\hline Venous obstruction (5): & PVO (4), SVCO (1) \\
\hline Hemolysis (3): & $\begin{array}{l}\text { Residual VSD (1), PS (1), } \\
\text { AR (1) }\end{array}$ \\
\hline $\begin{array}{l}\text { Infectious } \\
\quad \text { endocarditis (3): }\end{array}$ & Bacterial (2), Fungus (I) \\
\hline $\begin{array}{l}\text { Prosthetic valve } \\
\quad \text { dysfunction (2): }\end{array}$ & $\begin{array}{l}\text { SAM prosthesis (1), St. Jude } \\
\text { Medical Prosthesis (1) }\end{array}$ \\
\hline
\end{tabular}

Abbreviation: $A R=$ aortic regurgitation; $T R=$ tricuspid regurgitation; $M R=$ mitral regurgitation; $P S=$ pulmonary stenosis; $P R$ pulmonary regurgitation; $V S D=$ ventricular septal defect; $A S D=$ atrial septal defect; $P V O=$ pulmonary venous obstruction; $S V C O=$ superior vena cava obstruction

from physical growth; 3 received reconstruc tion of RVOT with implantation of a cadaveric pulmonary valve conduit homograft which was fixed in $4 \%$ formalin for 5 to 7 days and rinsed with lactate Ringer's solution for $6 \mathrm{~h}$ before use. At the reoperation performed 3 to 11 years later, the valve leaflets of the graft were found to be calcified, to have disappeared in 2 of them, with the graft walls showing a mild calcification and fibrin deposition.

Two patients manifesting prosthetic valve endocarditis survived the reoperation and another with postoperative endocarditis died from septicemia due to candida infection at the Dacron patch used for closure of VSD, despite the thorough removal of candida-infected lesions at reoperation. All of 5 patients with venous obstruction received nonabsorbable monofilament sutures at previous correction and manifested an obstruction caused by abnormal prliferation of the neointimal tissue at the site of anastomosis, for which the narrowed anastomosis site was enlarged with a porcine pericardial patch at reoperation. One with TAPVC of the supracardiac type received a pericardial patch for
TABLE III VALVULAR LESION AT REOPERATION (No. of patients)

\begin{tabular}{|c|c|}
\hline Valvular lesion & Dx at initial operation \\
\hline$A R(12)$ & $\begin{array}{l}\text { VSD (9): isolated (1); with AR (8) } \\
\text { TOF (1) } \\
\text { DORV (1) } \\
\text { Truncus Arteriosus (1) }\end{array}$ \\
\hline$T R(12)$ & $\begin{array}{l}\operatorname{VSD}(4) \text { : isolated (2); with } T R(1) ; \text { with } \\
\quad C O A(1) \\
\operatorname{TOF}(3) \\
A-V C D(2) \\
A S D(2) \\
\text { congenital AR with IE (1) }\end{array}$ \\
\hline$M R(11)$ & $\begin{array}{l}\text { VSD (6): with } M R(2) ; \text { isolated (1); } \\
\text { with } T R(1) ; \text { with CoA (1); } \\
\text { with PDA,MR(1) } \\
\text { A-VCD (3) } \\
\text { ASD (1) } \\
\text { congenital AR with IE (1) }\end{array}$ \\
\hline
\end{tabular}

Abbreviation: $D x=$ diagnosis; $A R=$ aortic regurgitation; $\quad V S D=$ ventricular septal defect; TOF=tetralogy of Fallot; DORV=double outlet right ventricle; $T R=$ tricuspid regurgitation; $A$ $V C D=$ atrioventricular canal defect; $I E=$ infective endocarditis; $\quad \operatorname{Co} A=$ coarctation of aorta; $A S D=$ atrial septal defect; $M R=$ mitral regurgitation; $P D A=$ patent ductus arteriosus

closure of a large ASD and another with complete A-VCD underwent closure of an ASD with a Dacron patch. However, at reoperation these two were found to have a complete obstruction of the right pulmonary vein, for which correction was not successful, leading to death 6 days and 37 days later, respectively.

The major causes of reoperation were analyzed in relation with the interval betewen previous and subsequent operation. The average intervals were 3.9 months in hemolysis and 10.4 month in pulmonary venous obstruction (PVO) and, among the valvular lesions, 31.7 months in MR, 55.2 months in TR and 79.0 months in AR, and more than 5 years in residual septal defect. It was noted that MR tended to demand an earlier reoperation than AR or TR.

The CTR was measured before and after either of the operations. In most patients with residual MR and venous obstruction, this value decreased after previous operation and increased rapidly before reoperation 
while its gradual deterioration was seen in those with residual septal defect, TR, and RVOT stenosis.

The operation was repeated three times in 3 patients. One boy with VSD-associated AR underwent repetition of aortic valvuloplasty at the ages of 3 and 10 years. Another boy who had previously undergone mitral annuloplasty for VSD-associated MR at 1 year and 11 months of age, progressed to replacement of the mitral valve with a St. Jude Medical valve prosthesis at two years, and despite the antiplatelet treatment with aspirin, necessitated repeated mitral valve replacement because of a thrombosed mechanical prosthesis at 2 years and 10 months. A girl with complete A-VCD underwent repetition of bilateral mitral annuloplasty by Kay's method and of mitral advancement of the anterior mitral leaflet at the ages of 4 and 10 years, and finally received replacement of the mitral valve with a St. Jude Medical prosthesis at 14 years.

With 61 reoperations performed in 58 patients, 5 early and 4 late deaths were encountered. The causes of the early deaths were severe low cardiac output syndrome in 3 ; renal failure in one; and a stuck valve of the mechanical prosthesis in one. The late deaths were related to cardiac symptoms, i.e. either cardiac failure or fatal arrhythmias. Of the 49 survivors, 3 required careful follow-ups or restriction of exercise because of significant residual lesions but the other 46 progressed through an uneventful postoperative course.

\section{COMMENT}

Advances in cardiac surgery have permitted the expansion of the indications for total correction of CHD to involve not only children but also infants and neonates. Reoperation after CHD total repair has been complicated by such issue as residual lesions and the recipient's physical growth? ${ }^{2-6}$

In our series the most frequent cause of reoperation was valvular lesions because valvuloplasty was accepted as the first-choice operation for valvular incompetence in our institute. Postoperative AR was mostly associated with VSD and improved after aortic valvuloplasty and aortoplasty of our maneuver as previously described? In contrast, postoperative $\mathrm{MR}$ was seen after repair of either VSD or A-VCD ${ }^{8}$ concomitant with an MR lesion, but it was noted to occur also in some patients with MR-free VSD? Those patients with evidence of moderate to severe MR on the echocardiogram should be followed carefully, and the onset of symptoms intrinsic in heart failure or the deterioration should be managed by a timely reoperation. The acceptable outcome of mitral repair has not always been attained with Kay's maneuver in the single mitral commissure. However, we usually avoided applying mitral annuloplasty in the bilateral comissures to prevent a late mitral stenosis. Postoperative TR occurred due to technical difficulties in placing stitches at the tricuspid leaflets for VSD closure and due care should be taken during its closing through the trans-pulmonary or trans-right ventricular approach.

PS with a significant pressure gradient across RVOT $4,6,10,11$ after primary repair of TOF raised hemodynamic problems in our patients only when the gradient was over 50 $\mathrm{mmHg}$. However, there were minor hemodynamic problems with $\mathrm{PR}$ after reconstruction of RVOT with or without a valved patch and we encountered only one reoperative patient with significant PR. For primary repair of TOF, therefore, a complete repair of PS seemed to be more important than PRrelated problems.

Residual septal defect after closure of VSD or ASD was another major cause for reoperation in 29 patients in our series. The leakage in VSD cases occurred mostly at the site of antero-septal commissure and careful attention should be paid at this location. In most patients with a residual shunt ratio over $30 \%$ or a pulmonary pressure over $50 \mathrm{mmHg}$ due to the lesion, reoperation was performed because of persistent postoperative congestive heart failure. A possible residual VSD was carefully monitored by clinical and echocardiographic checkups for at least the first week following VSD closure. In postoperative residual VSD cases there was a certain grace allowed for timing of reoperation. Nonetheless, patients manifesting hemolysis resulting from residual VSD should be monitored carefully on the intensity of the anemia and renal dysfunction induced by hemolysis, taking into account that they may progress to require an imminent 
reoperation.

The cause of obstruction in patients with postoperative venous obstruction ${ }^{12-17}$ was invariably abnormal intimal proliferation at the anastomosis sites, causing the rapid onset of congestive heart failure. To prevent this complication we suggest the avoidance inserting artificial material into the atrium and non-absorbable stitches around the pulmonary vein, which seems to be one of the factors in stimulation of intimal proliferation!2 At the onset of this complication, earlier timing for reoperation is important in patients with postoperative echocardiogram and CTR changes. These patients usually developed a rapid deterioration of left heart failure. The onset of such PVO complications is usually seen within 1 year of CHD repair and it seems that adequate follow-up at this time is significant in patients with TAPVC and complete A-VCD.

With CHD repair in children, the operation should be followed carefully with awareness of the patient's physical growth. Based on our experience, the indications for $\mathrm{CHD}$ reoperation during follow-up are as follows:

1. Postoperative changes in the echocardiogram as well as an increase in CTR and symptoms of congestive heart failure which indicate:

a) Moderate to severe valvular insufficiency,

b) Residual septal defect giving a shunt ratio over $30 \%$ or a pulmonary pressure over $50 \mathrm{mmHg}$, or

c) Residual RVOT stenosis with a pressure gradient across RVOT over 50 $\mathrm{mmHg}$.

MR in particular should be carefully followed, and those cases of regurgitation lesions and hemolysis due to residual shunt should also be carefully followed.

2. Earlier timing for correction of pulmonary venous obstruction due to intimal proliferation, of prosthetic valvular dysfunction.

3. Postoperative severe infective endocarditis.

\section{Acknowledgments}

We thank Dr. I.M. Rebeyka and Ms. N. Hoshino for reviewing the manuscript.

\section{REFERENCES}

1. MILLIKAN SJ, PUGA FJ, DANIELSON GK, SCAFF HV, LULSRUD PR, MAIR DD: Staged surgical repair of pulmonary atresia, ventricular septal defect, and hypoplastic, confluent pulmonary arteries. J Thorac Cardiovasc Surg 91: 818, 1986

2. ATTIE F, SORIANO FL, OVSEYEVITZ J, MARTINEZ J, MORENO MG, BUENDIA A, DOMINGUEZ RC, RICHHEIMER R: Late results of mitral replacement with the Björk-Shiley prosthesis in children under 16 years of age. $J$ Thorac Cardiovasc Surg 91: 764, 1986

3. MILANO A, VOUHE PR, VERNANT FB, GOUGE PD, TRINQUET F, ROUX PM, LECA F, NEVEUX JY: Late results after left-sided cardiac valve replacement in children. $J$ Thorac Cardiovasc Surg 92: 218, 1986

4. ABRIL E, BJORK VO, IVERT T, OLIN C: Reconstruction of the right ventricular outflow tract in patients with tetralogy of fallot. Scand J Thor Cardiovasc Surg 16: 33, 1982

5. HENZE A, LINDBLOM D, BJÖRK VO: Mechanical heart valve in children. Scand $J$ Thor Cardiovasc Surg 18: 155, 1984

6. ZHAO HX, MILLER DC, REITZ BA, SHUMWAY NE: Surgical repair of tetralogy of Fallot. Long-term follow up with particular emphasis on late death and reoperation. $J$ Thorac Cardiovasc Surg 89: 204, 1985

7. HISATOMI $\mathrm{K}$, KOSUGA $\mathrm{K}$, ISOMURA $\mathrm{T}$, AKAGAWA H, OHISHI K, KOGA M: Ventricular septal defect associated with aortic regurgitation. Ann Thorac Surg 43: 363, 1987

8. ABBRUZZESE PA, LIVERMORE J, SUNDERLAND CO, NUNLEY DL, ISSENBERG $\mathrm{H}$, KHONSARI S, GARCIA CE, STARR A: Mitral repair in complete atrioventricular canal. Ease of correction in early infancy. $J$ Thorac Cardiovasc Surg 85: 388, 1983

9. KOSUGA K, NAKAMURA $\mathrm{H}$, ISOMURA $\mathrm{T}$, OHRYOJI A, AKAGAWA H, AOYAGI $\mathrm{N}$, SAKAMOTO T, KOGA Y, TAJIRI T, OHISHI K, KOGA M: Surgical treatment for mitral regurgitation (MR) in childhood (younger than 12 years). J Cardiovasc Surg 24: 434, 1983

10. ABE T, ASAI Y, SUGIKI K, KOMATSU S: Reoperation after initial correction of tetralogy of Fallot. J Cardiovasc Surg 26: 568, 1985

11. SCHAFF HV, DIDONATO RM, DANIELSON GK, PUGA FJ, RITTER DG, EDWARDS WD, MCGOON DC: Reoperation for obstructed pulmonary ventricle pulmonary artery conduits. Early and late results. J Thorac Cardiovasc Surg 88: 334,1984

12. SCHAFERS HJ, LUHMER I, OELERT H: Pulmonary venous obstruction following repair of total anomalous pulmonary venous drainage. Ann Thorac Surg 43: 432, 1987

13. JONAS RA, SMOLINSKY A, MAYER JE, CASTANEDA AR: Obstructed pulmonary venous drainage with total anomalous pulmonary venous connection to the coronary sinus. Am J Cardiol 59: 431,1987 
14. MAZZUCCO A, RIZZOLI G, FRACASSO A, STELLIN G, VALFRE C, PELLEGRINO P, BORTOLOTTI U, GALLUCCI V: Experience with operation for total anomalous pulmonary venous connection in infancy. $J$ Thorac Cardiovasc Surg 85: 686, 1983

15. BYRUM CJ, DICK $M$, BEHRENDT DM, ROSENTHALL A: Repair of total anomalous pulmonary venous connection in patients younger than 6 months old. Circulation 66(Suppl I): 208, 1982
16. FLEMING WH, CLARK EB, DOOLEY KJ, HOFSCHIRE PJ, RUCKMAN RN, HOPEMAN AR, SARAFIAN L, MOORING PK: Late complication of following surgical repair of total anomalous pulmonary venous return below the diaphragm. Ann Thorac Surg 27: 435, 1979

17. ABBRUZZESE PA, ISSENBERG $\mathrm{H}$, COBANOGLU A, GARCIA C, NUNLEY D, STARR A: Superior vena cava obstruction after Mustard repair of d transposition of the great arteries. Scand J Thor Cardiovasc Surg 18: 5, 1984 